\title{
Warm-up effects in free-operant avoidance in a shuttlebox
}

\author{
PHILIP N. HINELINE and LAUREN B. ALLOY \\ Temple University, Philadelphia, Pennsylvania 19122
}

In a study of free-operant avoidance in rats with a shuttle response, Riess and Farrar (1972) obtained rapid acquisition and proficient performance showing no warm-up effects. This latter result is of interest because warm-up effects are ubiquitous in rats' performances on other freeoperant avoidance procedures. As part of an attempt to isolate variables that control the warm-up, two replications of Riess and Farrar's procedure were undertaken. While rapid acquisition of avoidance was obtained, warm-up effects were evident in nearly all rats. Hence, warm-up in avoidance is not specific to the leverpress and wheel-turn responses, which are more commonly used for study of free-operant avoidance.

Warm-up effects are ubiquitous in avoidance conditioning; they are characterized by ineffective performance at the beginning of each avoidance session, relative to performance late in the preceding session. Warm-up effects are of some concern, for they constrain the designs of experiments, and they often necessitate the discarding of data from substantial portions of experimental sessions. The basis for warm-up is not well understood. Nor are there methods for eliminating it, other than by selection of subjects after pretraining, or by delivering presession shocks (Hoffman, Fleshler, \& Chorny, 1961), which would complicate the interpretation of most experiments. Warm-up occurs both on signaled avoidance procedures (e.g., Hoffman, 1966; Hoffman et al., 1961) and on unsignaled avoidance procedures (Sidman, 1953; Weissman, 1962). While it has been observed with pigeons (e.g., Foree \& LoLordo, $1970,1974)$ as well as with rats, it seems to be a feature that differentiates the performance of different species. Powell found that it occurs more reliably in hooded and albino rats than in black rats (Powell, 1972, 1976), and that it is apparently absent from performances of gerbils and of cotton rats (Powell, 1971; Powell \& Mantor, 1970; Powell \& Peck, 1969).

The topography of the specified avoidance response appears to have some bearing on warm-up. The effect has been reported most frequently with leverpress responses, partly because this is the most commonly used response in long-term studies, where warm-up

This research was accomplished with the support of Public Health Service research Grant MH-18432 from the National Institute of Mental Health. Preparation of the manuscript was supported by facilities of the Laboratory of Experimental Psychology at the University of Sussex. Reprints can be obtained from the senior author, Department of Psychology, Temple University, Philadelphia, Pennsylvania 19122. Lauren B. Alloy is currently a predoctoral student in psychology at the University of Pennsylvania. effects are most readily detected. Warm-up has also been encountered with a wheel-turn response (Anderson \& Nakamura, 1964). Hineline (1966) found that allowing the animals to avoid by lever holding instead of by repeated pressing produced some reduction in the warmup, but did not eliminate it entirely. On the other hand, Reiss and his colleagues have carried out several experiments with a free-operant shuttle response, finding very quick acquisition, and virtually no warm-up effects (e.g., Martin \& Riess, 1969; Riess, 1970). Riess and Farrar (1972) documented these features with detailed data. In all eight of their rats, they found no evidence of warm-up; to the contrary, their animals tended to respond more frequently during the first half of each daily session.

In our laboratory, Smith (1973) used a free-operant shuttle procedure in an experiment addressed to other issues. He found quick and reliable acquisition, as Riess and Farrar (1972) had reported, but pronounced warm-up effects were observed in the course of his experiment. This differing outcome could have been due to procedural differences of session length and shock intensity, as well as to differing strain and sex of rats. The differences of procedure and results suggested that the free-operant shuttle situation is one in which variables controlling the warm-up could be isolated. To this end, more exact replications of Riess and Farrar's procedure were undertaken. The results are reported below.

\section{EXPERIMENT 1}

The first experiment was designed as a close, but not exact, replication of the Riess and Farrar (1972) experiment. The schedule, the shock intensity, and the age, sex, and strain of rats were very similar to those used by Riess and Farrar. The apparatus differed slightly, in that there was no hurdle dividing the shuttlebox, conforming to the work by Smith (1973). 


\section{Method}

Subjects. Eight naive female rats of the Sprague-Dawley strain, designated B-1 through B-8, were received from a commercial supplier (Camm Research Institute) when 55-65 days old. They were housed in individual cages with free access to food and water. Each rat was handled $5 \mathrm{~min} /$ day for 1 week before exposure to the main procedure.

Apparatus. The conditioning chamber was a modified Lehigh Valley Electronics shuttlebox measuring $46 \times 20.6 \times 20.5 \mathrm{~cm}$, with a grid floor of stainless steel rods, $2 \mathrm{~mm}$ in diameter and spaced $1.1 \mathrm{~cm}$ apart, center to center. The grids were wired to the shock scrambler such that no single circuit supplied any two adjacent rods. The grid floor assembly tilted slightly about a center pivot; in combination with a microswitch, this permitted automatic detection of shuttle responses. The shuttlebox was housed in a sound-resistant, ventilated wooden chest; masking noise was supplied by a Grason-Stadler Model 901B white-noise generator. A BRS-Foringer constant-current shock generator (Model SG-901) and electromechanical scrambler (Model SC-901) provided shocks, with intensity of $2.0 \mathrm{~mA}$ and duration of $.25 \mathrm{sec}$. Control equipment was located in a separate room.

Procedure. The rats were given daily 20-min conditioning sessions with Sidman's (1953) free-operant avoidance procedure, using a shock-shock (SS) interval of $5 \mathrm{sec}$, and a response-shock (RS) interval of $20 \mathrm{sec}$. Crossing over the midpoint of the shuttlebox, as detected by the tilt mechanism, constituted a response. No exteroceptive feedback was provided other than the click of the microswitch activated by the tilt. A diffuse houselight was on during sessions. Each session began with a RS interval. During each session, response and shock totals were recorded every $5 \mathrm{~min}$. The two animals with highest shock rates (poorest performance) were run for 7 sessions; all others were run for 21 sessions.

\section{Results}

Summary measures of performance during the first 10 sessions of training are indicated by circular data points in Figure 1. Comparable data derived from the report by Riess and Farrar (1972) are plotted here with triangular data points. First-session response rates were very similar in the two experiments. Then the response rates of Riess and Farrar's animals increased more quickly than those of the present subjects, but by Session 5 these rates were again similar. Thus, before $2 \mathrm{~h}$ of training had elapsed, similar asymptotic rates had been reached. This constitutes rapid acquisition for unsignaled free-operant avoidance. Shock rates indicate greater differences of outcome, however. Time to asymptote was the same as for response rates, but the means and ranges of performance in the present experiment differed substantially from those observed by Riess and Farrar. Only the two most proficient rats of the present experiment achieved the low range of shock rates that were achieved by all of Riess and Farrar's animals.

The differing outcomes originated mainly in differing warm-up effects, as shown by Figure 2. Riess and Farrar (1972) assessed within-sessions performance changes by computing the percent of total responses that occurred in the first half of each of their sessions. The mean values they obtained with this statistic are shown with triangular data points; the circular data plots show the same statistic for the present experiment.
EXP. I
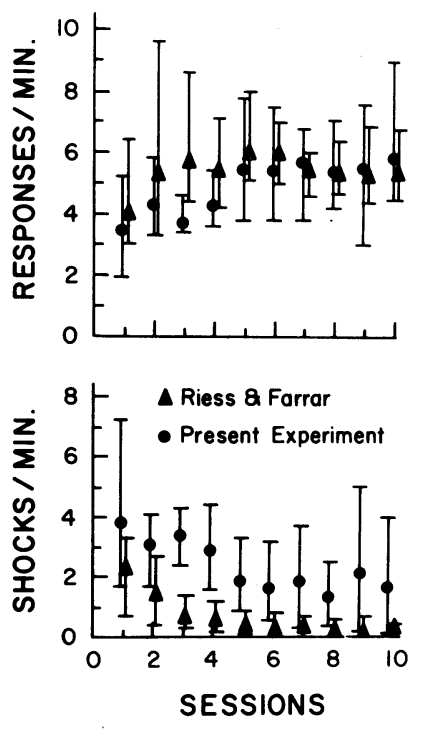

Figure 1. Mean response rates and shock rates and ranges of these rates taken across animals for successive 20-min sessions of avoidance training. Results from the present Experiment 1 are indicated with circular data points. Results reported by Riess and Farrar (1972) are indicated with triangular data points. The selection of data in the two experiments differed in one respect: The two least proficient avoiders were dropped from the analysis of data from the present experiment. This should tend to make the present performances appear superior to those obtained by Riess and Farrar.

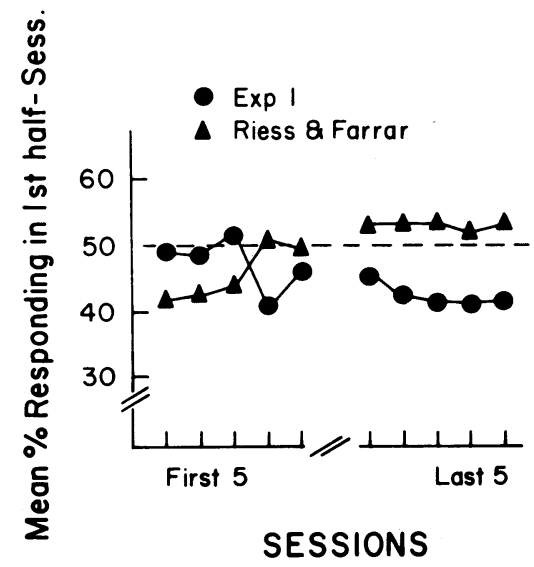

Figure 2. Percentages of responses occurring in the first half of each 20 -min session, for the first five and for the last five sessions. Means were taken across all animals in Riess and Farrar's (1972) experiment (triangular data points) and across the six most proficient avoiders in the present Experiment 1) circular data points).

In Session 1, some of the animals of the present experiment responded substantially more in the first half, while some responded substantially less, with the mean for the group lying near $50 \%$. The trend after the first session was toward smaller percentages of responding in the first half session. This pattern, indicating a warmup effect, persisted throughout the 21 sessions of the 
experiment; only one animal failed to show the effect. The results obtained by Riess and Farrar showed the opposite trend, starting with least responding early in sessions, changing to greater early-session responding by the last five sessions. Warm-up effects in the present experiment will be presented in more detail along with the results of Experiment 2.

\section{EXPERIMENT 2}

While Experiment 1 demonstrated rapid and reliable acquisition of the free-operant shuttle response in most animals, it clearly differed from the findings of Riess and Farrar (1972) with respect to warm-up effects. They reported that there were no such effects, while we found the warm-up effect in most animals. There was one major procedural difference between the two experiments, namely, the absence of a hurdle in the present Experiment 1 . Such a difference could be important, for it affects the topography of the response, the precision with which the response is defined, and the degree of feedback intrinsic to the response. Accordingly, a second replication seemed in order, using a hurdle with the same dimensions as that employed by Riess and Farrar.

\section{Method}

Subjects. Eight naive female rats of the Sprague-Dawley strain, designated $L-1$ through $L-8$, were received from a commercial supplier (Camm Research Institute) when 55-65 days old. Their housing and preexperimental handling were the same as for the animals in Experiment 1.

Apparatus. The apparatus was identical to that used in Experiment 1, except for the addition of a 1.75-in. $(4.5-\mathrm{cm})$ hurdle made of a stainless steel strip. The hurdle divided the shuttlebox into two equal compartments and was connected to a separate contact of the shock-scrambler circuit. Also, an optical viewing device was added to the enclosure that housed the shuttlebox, permitting direct observation of the subjects.

Procedure. The conditioning and data-recording procedures were the same as in Experiment 1, with the following addition: For the first 7 days of training, an experimenter watched each

EXPERIMENT I
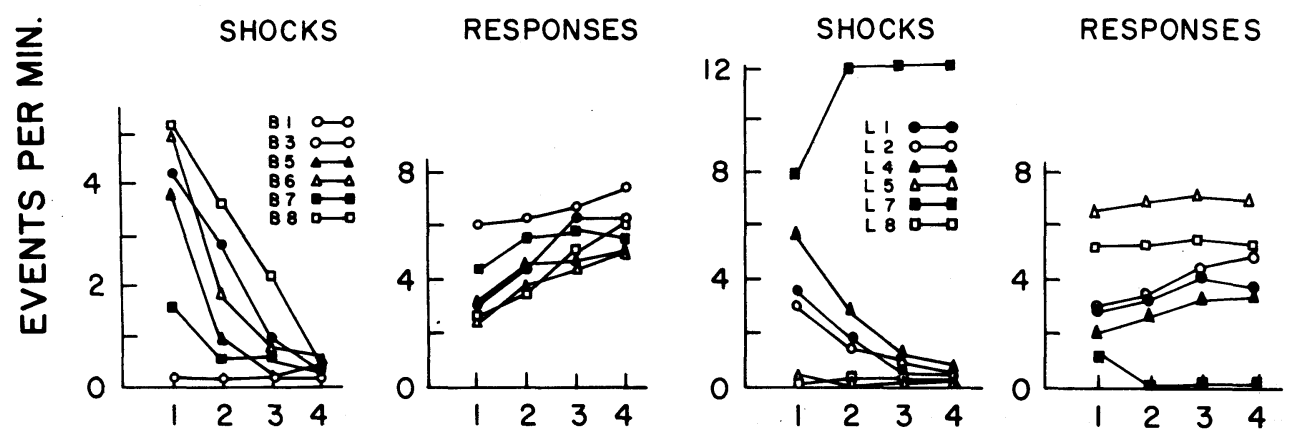
20 -min session, verifying that whenever a hurdle cross occurred, the equipment recorded a response at the moment when the forepaws of the subject touched the grid of the new compartment. As before, the two animals with highest shock rates were run for 7 sessions; all others were run for 21 sessions.

\section{Results}

The general outcome was similar to that of Experiment 1 . In terms of responses and shocks per session, first-session performances were slightly inferior in the present experiment, but asymptotic performances were reached slightly earlier-in the fourth, instead of the fifth, session. As in Experiment 1, the asymptotic response rates were similar to those of Riess and Farrar's (1972) experiment, while the asymptotic shock rates were much higher, indicating less proficient avoidance than Riess and Farrar obtained. Direct observation indicated that the animals were indeed receiving the shocks. One animal, L-7, was aberrant, in that it was the only one that was ever observed to perch on the hurdle instead of jumping over it. Details of this animal's behavior will be described below.

Warm-up effects were again evident, as revealed by Riess and Farrar's (1972) percentage measure, giving results similar to those shown for Experiment 1 in Figure 2. Warm-up effects observed in both of the present experiments are portrayed in more detail by Figure 3, which shows within-sessions changes in shock rates and response rates for the last five sessions of training. As shown in the left side of the figure, five of the six avoiders in Experiment 1 gave shock-rate plots of negative slope, indicating warm-up effects. The adjacent plots showing corresponding response rates indicate warm-up effects for all six of these animals. Animals from Experiment 2 are represented in the right half of the figure. The two most proficient avoiders, L-5 and L-8, showed virtually no warm-up. Rats L-1, L-2, and L-4 showed substantial warm-up effects, revealed by

\section{EXPERIMENT II}

\section{QUARTERS OF SESSIONS}

Figure 3. Response rates and shock rates during successive quarters of the 20 -min avoidance sessions. Each plot represents an individual rat; means were computed for each quarter session, over Sessions 17 21. The left half of the figure represents Experiment 1, the right half represents Experiment 2. 
decreasing shock rates and increasing response rates within sessions. Judging from these measures, Rat L-7 showed the opposite of a warm-up. However, for this animal, the standard measures are misleading.

Subject L 7 proved to be a special case. Initially, there was substantial shuttle responding, but this decreased rapidly, with a corresponding increase of shock rate. However, by observing the subject through the viewing device, it was discovered that this rat was learning to balance on top of the hurdle with tail raised, avoiding the shociss in this way instead of with the normal hurdle-cross response. In addition, throughout the 21-day experiment, the experimenter observed that during the first quarter of each session, this rat performed the hurdle-cross response. By the beginning of the second quarter of each session, however, the subject had resumed the balancing response and did this increasingly through the remaining two quarters. Hence, this rat showed a warm-up effect, with balancing on the hurdle as the avoidance response.

\section{DISCUSSION}

In some general respects, the present results did not differ greatly from those obtained by Riess and Farrar (1972). A majority of animals rapidly acquired the shuttle response, giving shock rates that are low in comparison to those commonly obtained with a leverpress response. There was little evidence of bursts of responses, or of other shock-elicited response patterns that could interfere with efficient avoiding.

However, while Riess and Farrar (1972) found no warm-up effects, nearly all of the present animals showed pronounced warm-up effects. This result thwarted our overall research strategy, for we had hoped to use the absence of warm-up on Riess and Farrar's procedure as a basis for isolating procedural features that contribute to the warm-up effect.

The basis for differences between outcomes in the present experiments and that of Riess and Farrar (1972) is not obvious, for the apparatus and procedures were closely similar in the two laboratories. Potential differences based upon shock delivered on the hurdle, or upon methods for detecting responses, were ruled out by extensive direct visual observation. The subjects in the two studies were of similar age and sex and were derived from the Wistar strain. There was a difference in pretraining treatment, in that the rats used by Riess and Farrar had been raised in an "activity cage environment." However, even this cannot account for much of the difference in outcomes, for in a study by Riess and Plaut (Note 1), "control" animals' performances, while statistically inferior to those of "activity cage" animals, were still substantially superior to those of the present experiments, where rearing conditions resembled those "control" conditions.

If one looks only at late-session performances (final $5 \mathrm{~min}$ of each session) in the present experiments, the results resemble those reported by Riess and Farrar (1972) and by Riess and Plaut (Note 1). This further supports the conclusion that, while we failed to identify the variables producing the differences between our outcomes and theirs, the major feature of these differences consists in presence vs. absence of warm-up effects.
The present results extend the demonstrated generality of warm-up effects; warm-up in avoidance is clearly not a responsespecific phenomenon.

\section{REFERENCE NOTE}

1. Riess, D., \& Plaut, S. M. Sidman avoidance acquisition as a function of sex and enriched environment. Unpublished manuscript, 1970. (Available from the Psychology Department, Galesburg State Research Hospital, Galesburg, Illinois 61401.)

\section{REFERENCES}

Anderson, N. H., \& Nakamura, C. Y. Avoidance decrement in avoidance conditioning. Journal of Comparative and Physiological Psychology, 1964, 57, 196-204.

ForEe, D., \& LoLordo, V. N. Signalled and unsignalled freeoperant avoidance in the pigeon. Journal of the Experimental Analysis of Behavior, 1970, 13, 283-290.

Foree, D., \& LoLordo, V. N. Transfer of control of the pigeon's key peck from food reinforcement to avoidance of shock. Journal of the Experimental Analysis of Behavior, 1974, 22, 251-259.

Hineline, P. N. The warm-up effect in avoidance conditioning. Unpublished doctoral dissertation. Harvard University, 1966.

HofFMAN, H. S. The analysis of discriminated avoidance. In W. K. Honig (Ed.), Operant behavior: Areas of research and application. New York: Appleton-Century-Crofts, 1966.

Hoffman, H. S., Fleshler, M., \& Chorny, H. Discriminated bar-press avoidance. Journal of the Experimental Analysis of behavior, 1961, 4, 309-316.

Martin, L. K., \& RIEss, D. Effects of US intensity during previous discrete delay conditioning on conditioned acceleration during avoidance extinction. Journal of Comparative and Physiological Psychology, 1969, 69, 196-200.

PowEll, R. W. Free-operant (Sidman) avoidance in field-raised and laboratory-raised wild rats. Journal of Comparative and Physiological Psychology, 1971, 75, 216-225.

Powell, R. W. Analysis of warm-up effects during avoidance in wild and domesticated rodents. Journal of Comparative and Physiological Psychology, 1972, 78, 311-316.

PoWELL, R. W. A comparison of signalled vs. unsignalled freeoperant avoidance in wild and domesticated rats. Animal Learning \& Behavior, 1976, 4, 279-286.

Powell, R. W., \& Mantor, H., JR. Shaping of free-operant avoidance in the wood rat, Nectoma floridana. Psychonomic Science, 1970, 20, 263-265.

Powell, R. W., \& PECK, S. Running-wheel activity and lever-press avoidance in the Mongolian gerbil. Journal of the Experimental Analysis of Behavior, 1969, 12, 779-789.

RIEsS, D. Secondary self-punitive behavior: Effects of periodic punishment of Sidman avoidance by a Pavlovian CS + . Psychonomic Science, 1970, 21, 185-187.

RIEss, D., \& FarRAR, C. H. Unsignalled avoidance in a shuttlebox: A rapid-acquisition, high-efficiency paradigm. Journal of the Experimental Analysis of Behavior, 1972, 18, 169-178.

SIDMAN, M. Two temporal parameters in the maintenance of avoidance behavior in the white rat. Journal of Comparative and Physiological Psychology, 1953, 46, 253-261.

SмIтн, G. D. Extinction of free-operant avoidance in rats. Unpublished doctoral dissertation. Temple University, 1973.

Weissman, A. Nondiscriminated avoidance behavior in a large sample of rats. Psychological Reports, 1962, 10, 591-600.

(Received for publication August 31, 1978.) 